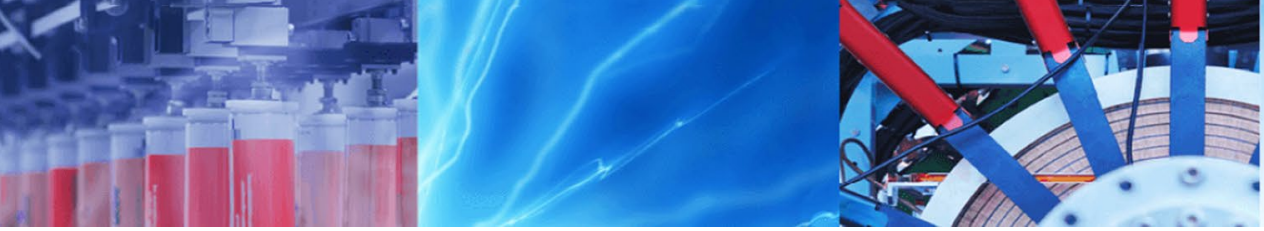

Research Article

\title{
Theoretical and experimental study of infrared spectral data of 2-bromo-4-chlorobenzaldehyde
}

\author{
Cemal Parlak ${ }^{1} \cdot$ Ponnadurai Ramasami ${ }^{2,3}$
}

Received: 3 April 2020 / Accepted: 19 May 2020 / Published online: 1 June 2020

(c) Springer Nature Switzerland AG 2020

\begin{abstract}
Infrared (IR) spectroscopy is one of the most common spectroscopic techniques and serves as an effective tool for characterizing compound and solvent interactions. In this research, experimental and theoretical spectral investigation and conformational analysis of 2-bromo-4-chlorobenzaldehyde were performed by IR spectroscopy and density functional theory (DFT). The solvent effect on carbonyl stretching vibration and the correlations between the experimental IR data for different solvents scales were also investigated. The reliability of a suitable theoretical model for the solvent effect was evaluated using experimental data. The scale from linear solvation energy relationships obtained using both experimental and theoretical data is useful to study solvent effect.
\end{abstract}

Keywords IR spectra · Di-halogenated benzaldehydes · Solvent effect · DFT · LSER

\section{Introduction}

IR spectroscopy is a useful analytical technique for both qualitative and quantitative analysis and it is based on molecular vibrational transitions. Powders, films, liquids, solutions, pastes, fibres, gases and surfaces can all be examined with IR technique. It is a useful tool to identify functional groups in organic and inorganic compounds. Different functional groups absorb different ranges of frequencies. The polarity of the solvent has influence on IR spectra of the compounds because of the interaction between solvent and compound and this is known as solvent effect. Solvent effects on IR data are well known [1-3] and characteristic IR stretching vibrations have been investigated $[4,5]$.

Benzaldehyde derivatives (aromatic aldehydes) are commonly employed in the field of pharmaceutical chemistry and in the chemical industry in the production of flavoring agents, agrochemicals, cosmetics, textiles, dyes as well as ligands in metal coordination chemistry. For example, substituted benzaldehydes can be designed to increase the oxygen affinity of human hemoglobin and to inhibit the sickle erythrocytes. Further, substituted chalcones obtained by using with benzaldehydes derivatives show anti-bacterial, anti-tumor, anti-inflammatory, antifungal, anti-microbial and anti-oxidant properties $[6,7]$.

Benzaldehyde and its derivatives have been the subject of several spectroscopic studies [6-19]. On the other hand, there are several approaches such as KirkwoodBauer-Magat (KBM) [20], solvent acceptor number (AN) [21], Swain [22] and linear solvation energy relationships (LSER) [23] scales in order to determine solvent influence on IR and Raman spectra. The KBM scale presented in 1937 was the first theoretical equation. Other scales were also developed between 1978 and 1983. These solvent parameters have been used to explain solvent effect for a variety of the compounds. In 2001, the theoretical carbonyl stretching frequencies of dialkyl ketones in seven different

Ponnadurai Ramasami, p.ramasami@uom.ac.mu | 'Department of Physics, Science Faculty, Ege University, 35100 Izmir, Turkey. ${ }^{2}$ Computational Chemistry Group, Department of Chemistry, Faculty of Science, University of Mauritius, Réduit 80837, Mauritius. ${ }^{3}$ Department of Chemistry, University of South Africa, Private Bag X6, Florida 1710, South Africa. 
organic solvents were investigated by KBM and AN [24]. In 2002-2013, only the experimental carbonyl stretching frequencies of 5-methyl-7-methoxy-iso-flavone [25], 2-acetylthiophene [26], trimethyl phosphate [27], methyl methacrylate [28], 1,3-indanedione [29], butyl methacrylate [30], ethyl methacrylate [31], N-tert-butylacetamide [32] in various solvents were investigated by LSER, $\mathrm{KBM}$ or AN. Both experimental and theoretical studies employing these equations between 2012 and 2015 were related to flurbiprofen [33] and vinyl acetate [34]. Recently, theoretically, some IR and NMR shifts of the benzyne (KBM and $\mathrm{AN}$ ) [35] and carbine (KBM and LSER) [36] complexes were investigated by LSER, KBM or AN whereas $\mathrm{NH}$ and carbonyl stretching frequencies of 1-(4-pyridyl) piperazine [37] and 4-bromo-2-halogonebenzaldehyde [38] correspondingly were investigated by Swain, LSER, KBM and AN.

Even though, as outlined above, influences of different substituents on benzaldehydes such as dihydroxybenzaldehydes, fluorobenzaldehydes or 2-bromo-5-fluorobenzaIdehyde [6-19] were studied by vibrational spectroscopy and density functional theory (DFT), to the best of our knowledge, in literature, there is no experimental and theoretical IR spectral investigation of 2-bromo-4-chlorobenzaldehyde (Cas No: 84459-33-6). The current investigation is in continuation with our interests in studying the experimental vibrational spectra of di-halogenated benzaldehydes as 4-chloro-3-fluorobenzaldehyde [6] and 2-fluoro4-bromobenzaldehyde [7], and the theoretical solvent effect on carbonyl stretching of 4-chloro-3-halogenobenzaldehydes [39] and 4-bromo-2-halogonebenzaldehyde (Cas No: 158435-41-7 of 4-bromo-2-chloroebenzaldehyde) [38]. The main aim of this research was to characterize the IR bands of 2-bromo-4-chlorobenzaldehyde by experimental (IR spectroscopy) and DFT methods. Further, solvent effect on carbonyl stretching of the compound was studied.

\section{Experimental}

All solvents and 2-bromo-4-chlorobenzaldehyde were purchased from Merck and Sigma-Aldrich Co., respectively. IR spectra of 2-bromo-4-chlorobenzaldehyde in solid phase and in n-hexane, cyclohexane, chloroform, benzene, toluene as non-polar solvents and ethanol, 2-propanol, methanol as polar solvents were recorded by Bruker Optics IFS66v/s FTIR spectrometer and Perkin Elmer FTIR spectrophotometer correspondingly. All spectra were reported in the region of $4000-400 \mathrm{~cm}^{-1}$ at $2 \mathrm{~cm}^{-1}$ resolutions. Concentrations of the compound in solutions were between 0.21 and $0.25 \mathrm{~mol} / \mathrm{l}$.

\section{Calculations}

DFT methods are widely used for the quantum mechanical calculations of the different structures. The accuracy of theoretical predictions strongly depends on chosen functional and basis set. Methods, functional and basis sets chosen in this search showed quite accurate results for parameters of the experimentally single crystal structures of these type compounds [6, 7]. Gas phase optimization process of trans and cis forms of 2-bromo-4-chlorobenzaldehyde in $C_{s}$ symmetry (Fig. 1) was performed at the HF, MP2 and B3LYP level of theory using the aug-cc-pVDZ basis set in Gaussian 09 [40]. For the gas phase optimization, $6-311+G(3 d f, p)$ and $6-31 G(d, p)$ basis sets were also used with B3LYP. The computations for the liquid phase in the non-polar or polar solvents were conducted using B3LYP/6-31G $(d, p)$ method and the polarizable continuum model. Potential energy distribution (PED) was computed by the program of vibrational energy distribution analysis 4 [41]. Experimental and theoretical carbonyl stretching frequency was correlated by KBM, AN, Swain and LSER solvent models as described earlier [39]. The solvent parameters of these models for the solvents used were taken from Ref. [39].

\section{Results and discussion}

\subsection{Structural analysis}

The conformational energy parameters of the trans and cis forms of 2-bromo-4-chlorobenzaldehyde in the gas phase are given in Table 1. We reported the conformational analyses of 4-bromo-2-chlorobenzaldehyde [38] and 4-chloro-3-bromobenzaldehyde [39], related to bromoand chloro-substituted benzaldehydes and showed that

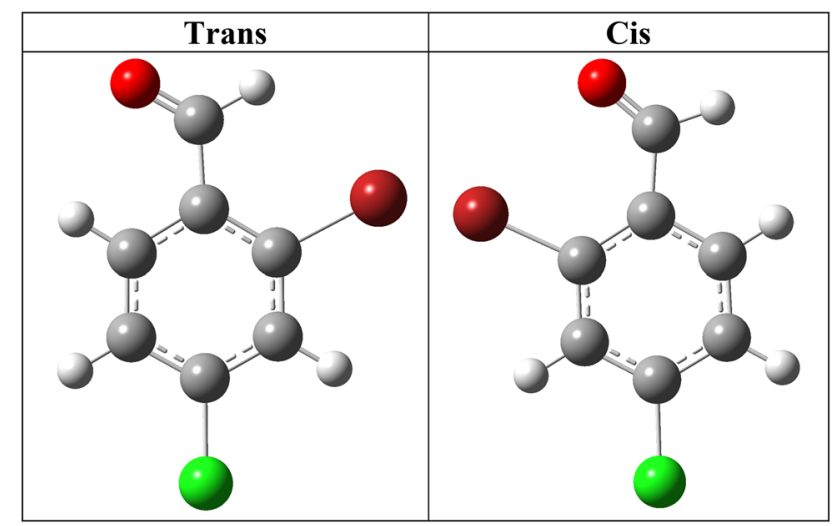

Fig. 1 Conformations of 2-bromo-4-chlorobenzaldehyde 
Table 1 Conformational energy parameters in the gas phase

\begin{tabular}{llllrl}
\hline Method & Conformer & Energy (Hartree) & $\begin{array}{l}\text { Relative } \\
\text { energy (kcal/ } \\
\text { mol) }\end{array}$ & $\begin{array}{l}\text { Mole frac- } \\
\text { tion (\%) }\end{array}$ & $\begin{array}{l}\text { Dipole } \\
\text { moment } \\
\text { (Debye) }\end{array}$ \\
\hline HF/aug-cc-pVDZ & Trans & -3374.19196835 & 0.00 & 99.8 & 1.65 \\
& Cis & -3374.18618258 & 3.63 & 0.2 & 3.54 \\
MP2/aug-cc-pVDZ & Trans & -3375.61202079 & 0.00 & 98.7 & 2.01 \\
& Cis & -3375.60795523 & 2.55 & 1.3 & 3.72 \\
B3LYP/aug-cc-pVDZ & Trans & -3378.78588833 & 0.00 & 98.8 & 1.91 \\
& Cis & -3378.78170327 & 2.63 & 1.2 & 3.22 \\
B3LYP/6-311+G(3df,p) & Trans & -3378.85926055 & 0.00 & 98.5 & 1.96 \\
& Cis & -3378.85529502 & 2.49 & 1.5 & 3.21 \\
B3LYP/6-31G(d,p) & Trans & -3376.27565886 & 0.00 & 99.2 & 1.60 \\
& Cis & -3376.27115219 & 2.83 & 0.8 & 3.95 \\
\hline
\end{tabular}

the trans isomer is more stable in the gas phase and in solutions for both compounds. For all levels of theory, the trans conformer of 2-bromo-4-chlorobenzaldehyde is more stable than cis and its relative percentage is almost $100 \%$. Further, gas phase computations using MP2, HF and B3LYP with the aug-cc-pVDZ basis set and the use of B3LYP with the $6-311+G(3 d f, p)$ and $6-31 G(d, p)$ basis sets do not show any change. On comparing the results of expensive MP2/aug-cc-pVDZ calculations, it is seen that other levels of theory can be used for such classes of compounds. Turning to the conformer in solutions of 2-bromo-4-chlorobenzaldehyde, the energetic parameters are listed in Table 2. Trans forms of the compound in the solutions are also more stable than cis like in the gas phase. According to the energy calculations from hexane to dimethylsulfoxide, the compound prefers the trans conformer in the solutions with approximate probabilities of $98-93 \%$. Conformations with higher dipole moment are commonly less stable [6]. The results are similar for the compound in all solvents.

The computed bond lengths are in good agreement with our previous experimental values $[6,7]$. For example, carbonyl bond lengths of 4-chloro-3-fluorobenzaldehyde and 2-fluoro-4-bromobenzaldehyde in solid were found as $1.206 \AA$ and $1.233 \AA$ [6, 7]. For the compound studied in this work, this bond length has been computed as 1.217 $\AA$ and 1.218-1.220 $\AA$ (Table 3 ) in gas phase and in solutions, respectively. Similarly, $\mathrm{C}-\mathrm{Cl}$ and $\mathrm{C}-\mathrm{Br}$ bond lengths of these compounds were experimentally reported as
Table 2 Conformational energy parameters in solution

\begin{tabular}{lrlllll}
\hline Solvent B3LYP/6-31G(d,p) & $\varepsilon$ & \multicolumn{2}{l}{ Energy (Hartree) } & & $\%$ & \\
\cline { 7 - 8 } \cline { 6 - 7 } & & Cis & & Trans & & \\
\hline n-Hexane & 1.89 & -3376.27359817 & -3376.27753691 & & 1.5 & 98.5 \\
n-Heptane & 1.92 & -3376.27365157 & -3376.27757651 & & 1.5 & 98.5 \\
Cyclohexane & 2.02 & -3376.27383332 & -3376.27771085 & & 1.6 & 98.4 \\
1.4-Dioxane & 2.21 & -3376.27413369 & -3376.27793136 & & 1.7 & 98.3 \\
Tetrachloromethane & 2.24 & -3376.27415981 & -3376.27795045 & & 1.8 & 98.2 \\
Benzene & 2.28 & -3376.27422004 & -3376.27799440 & & 1.8 & 98.2 \\
Toluene & 2.38 & -3376.27435953 & -3376.27809591 & & 1.9 & 98.1 \\
Diethylether & 4.26 & -3376.27588425 & -3376.27917904 & & 2.9 & 97.1 \\
Chloroform & 4.81 & -3376.27610524 & -3376.27933203 & & 3.2 & 96.8 \\
Tetrahydrofuran & 7.52 & -3376.27688429 & -3376.27986329 & & 4.1 & 95.9 \\
Dichloromethane & 9.08 & -3376.27712873 & -3376.28002741 & & 4.4 & 95.6 \\
2-Butanol & 17.26 & -3376.27768876 & -3376.28039879 & & 5.3 & 94.7 \\
2-Propanol & 18.60 & -3376.27781738 & -3376.28048318 & & 5.6 & 94.4 \\
Acetone & 21.01 & -3376.28050768 & -3376.27785483 & & 5.7 & 94.3 \\
Ethanol & 24.60 & -3376.27795873 & -3376.28057552 & & 5.9 & 94.1 \\
Methanol & 32.60 & -3376.27807666 & -3376.28065225 & & 6.1 & 93.9 \\
Acetonitrile & 36.64 & -3376.27810951 & -3376.28067357 & & 6.2 & 93.8 \\
Dimethylsulfoxide & 47.00 & -3376.27819302 & -3376.28072768 & & 6.4 & 93.6 \\
\hline
\end{tabular}


Table 3 Carbonyl bond length $(\AA)$, frequency $\left(\mathrm{cm}^{-1}\right)$ and dipole moment (Debye) of the compound

\begin{tabular}{|c|c|c|c|c|c|}
\hline Medium B3LYP/6-31G(d,p) & Dipole moment & Bond length & $v(C=O)$ Theo. $^{a}$ & $v(C=0)$ Theo. $\|^{a}$ & $v(C=0) \operatorname{Exp}$. \\
\hline Solid & - & - & - & - & 1690 \\
\hline Gas & 1.60 & 1.217 & 1717 & 1723 & - \\
\hline n-Hexane & 1.78 & 1.218 & 1709 & 1715 & 1706 \\
\hline n-Heptane & 1.78 & 1.218 & 1709 & - & - \\
\hline Cyclohexane & 1.79 & 1.218 & 1709 & 1714 & 1705 \\
\hline 1.4-Dioxane & 1.81 & 1.218 & 1708 & - & - \\
\hline Tetrachloromethane & 1.81 & 1.218 & 1708 & - & - \\
\hline Benzene & 1.82 & 1.218 & 1707 & 1713 & 1701 \\
\hline Toluene & 1.83 & 1.218 & 1707 & 1713 & 1701 \\
\hline Diethylether & 1.93 & 1.219 & 1702 & - & - \\
\hline Chloroform & 1.95 & 1.219 & 1701 & 1707 & 1699 \\
\hline Tetrahydrofuran & 2.00 & 1.220 & 1699 & - & - \\
\hline Dichloromethane & 2.01 & 1.220 & 1698 & - & - \\
\hline 2-Butanol & 2.05 & 1.220 & 1697 & - & - \\
\hline 2-Propanol & 2.06 & 1.220 & 1696 & 1702 & 1704 \\
\hline Acetone & 2.06 & 1.220 & 1696 & - & - \\
\hline Ethanol & 2.07 & 1.220 & 1696 & 1701 & 1703 \\
\hline Methanol & 2.07 & 1.220 & 1695 & 1701 & 1702 \\
\hline Acetonitrile & 2.08 & 1.220 & 1695 & - & - \\
\hline Dimethylsulfoxide & 2.08 & 1.220 & 1695 & - & - \\
\hline
\end{tabular}

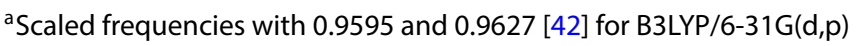

$1.732 \AA$ and $1.893 \AA$ whereas these bond lengths were computed as $1.750-1.753 \AA$ and $1.915-1.916 \AA$ in the gas phase or in solutions.

\subsection{IR study}

Experimental and theoretical IR data of 2-bromo-4-chlorobenzaldehyde are listed in Table 4 and the frequencies were scaled by 0.9683 [42]. The compound consists of fourteen atoms and has thirty-six normal vibrational modes. These modes by $C_{s}$ point group are given as $\Gamma_{\mathrm{v}}=25 \mathrm{~A}^{\prime}+11 \mathrm{~A}^{\prime \prime}$ irreducible representations. Experimental and simulated IR spectra of 2-bromo-4-chlorobenzaldehyde are shown in Fig. 2.

For the high frequency region, $\mathrm{CH}$ stretching vibrations of 4-chloro-3-fluorobenzaldehyde and 2-fluoro-4-bromobenzaldehyde were observed at 3094, 3069, $3042 \mathrm{~cm}^{-1}$ and $3086,3075,3032 \mathrm{~cm}^{-1}$, respectively $[6,7]$. The corresponding bands of the title compound are observed in the expected region as $3100,3088,3019 \mathrm{~cm}^{-1}$. One of the most important functional groups of the compound is the formyl group. Carbonyl and $\mathrm{CH}$ stretching vibrations of this group are observed at $1690 \mathrm{~cm}^{-1}$ and $2873 \mathrm{~cm}^{-1}$. Theoretical values were computed at $1709 \mathrm{~cm}^{-1}$ and $2878 \mathrm{~cm}^{-1}$. Observed band about $2932 \mathrm{~cm}^{-1}$ in IR spectrum is due to the Fermi resonance which occurs between $\mathrm{CH}$ stretching fundamental and overtone of $\mathrm{CHO}$ deformation band $[6$,
7]. The IR bands observed at $1392 \mathrm{~cm}^{-1}$ and $1001 / 988 \mathrm{~cm}^{-1}$ are assigned to $\mathrm{CH}$ rocking and wagging of formyl group. Theoretical values are found at $1380 \mathrm{~cm}^{-1}$ and $1000 \mathrm{~cm}^{-1}$. All peaks are observed in the expected region [6-19]. CF stretching vibration of para chloro-meta fluoro compound [6] was shown as $1253 \mathrm{~cm}^{-1}$. For the current study, $\mathrm{CBr}$ stretching vibration of para chloro-ortho bromo compound are dominated in two different bands as 1251 and $568 \mathrm{~cm}^{-1}$. Further, it can be mentioned that the $\mathrm{CBr}$ stretching of para bromo-ortho fluoro compound [7] were shown as $658 \mathrm{~cm}^{-1}$.

Table 3 gives experimental and theoretical data for solvent effect on carbonyl stretching frequency as one of the most important functional groups of the compounds. Figure 3 shows the experimental carbonyl stretching bands of 2-bromo-4-chlorobenzaldehyde in non-polar and polar solvents. The carbonyl stretching bands in solutions appear in the region of $1699-1706 \mathrm{~cm}^{-1}$. Theoretical frequencies (I) and (II) were multiplied by the scaling factor of 0.9595 and 0.9627 for the B3LYP/6-31G $(d, p)$ method, which were obtained in this study and reported [42]. These bands in the solvents were computed as the region of $1695-1709 \mathrm{~cm}^{-1}$ and $1701-1715 \mathrm{~cm}^{-1}$, respectively. These results show an obvious correlation for carbonyl frequency. The root mean square deviations (RMSD) of the theoretical and experimental frequencies for carbonyl stretching were found as $5.73 \mathrm{~cm}^{-1}$ and $8.09 \mathrm{~cm}^{-1}$ 
Table 4 Comparison of the experimental and computed vibrational frequencies $\left(\mathrm{cm}^{-1}\right)$

\begin{tabular}{|c|c|c|c|c|}
\hline \multirow[t]{3}{*}{ Mode } & \multirow{3}{*}{$\begin{array}{l}\text { Assignment } \\
\text { PED ( } \geq 10 \%)\end{array}$} & \multirow{3}{*}{$\begin{array}{l}\text { Experimental } \\
\text { IR }\end{array}$} & \multirow{2}{*}{\multicolumn{2}{|c|}{$\begin{array}{l}\text { B3LYP/6- } \\
311+\mathrm{G}(3 \mathrm{df}, \mathrm{p}) \\
\text { Trans }\end{array}$}} \\
\hline & & & & \\
\hline & & & IR & $I_{I R}$ \\
\hline $1\left(A^{\prime}\right)$ & $\mathrm{v}(\mathrm{CH})(95)$ & 3100 & 3113 & 2.93 \\
\hline $2\left(\mathrm{~A}^{\prime}\right)$ & $\mathrm{v}(\mathrm{CH})(95)$ & 3088 & 3106 & 2.82 \\
\hline $3\left(A^{\prime}\right)$ & $\mathrm{v}(\mathrm{CH})(94)$ & 3019 & 3087 & 0.08 \\
\hline $4\left(A^{\prime}\right)$ & $v(C H)(100)$ & 2873 & 2878 & 43.64 \\
\hline $5\left(A^{\prime}\right)$ & $v(C=0)(92)$ & 1690 & 1709 & 284.79 \\
\hline $6\left(A^{\prime}\right)$ & $\mathrm{v}(\mathrm{CC})(95)$ & 1578 & 1561 & 209.52 \\
\hline $7\left(\mathrm{~A}^{\prime}\right)$ & $v(\mathrm{CC})(85)+\beta(\mathrm{CH})(10)$ & $1554 / 1508$ & 1530 & 29.95 \\
\hline $8\left(A^{\prime}\right)$ & $v(\mathrm{CC})(42)+\beta(\mathrm{CH})(42)$ & $1460 / 1442$ & 1441 & 35.57 \\
\hline $9\left(A^{\prime}\right)$ & $\rho(C H)(45)+v(C C)(40)$ & 1392 & 1380 & 3.49 \\
\hline $10\left(A^{\prime}\right)$ & $v(\mathrm{CC})(45)+\rho(\mathrm{CH})(41)$ & 1372 & 1362 & 57.53 \\
\hline $11\left(A^{\prime}\right)$ & $v(C C)(88)$ & 1283 & 1269 & 3.58 \\
\hline $12\left(A^{\prime}\right)$ & $\mathrm{v}(\mathrm{CBr})(43)+\mathrm{v}(\mathrm{CC})(40)$ & 1251 & 1239 & 32.44 \\
\hline $13\left(A^{\prime}\right)$ & $\beta(\mathrm{CH})(45)+v(\mathrm{CC})(42)$ & 1198 & 1178 & 51.85 \\
\hline $14\left(A^{\prime}\right)$ & $\beta(\mathrm{CH})(70)+v(\mathrm{CC})(157)$ & 1123 & 1110 & 23.46 \\
\hline $15\left(A^{\prime}\right)$ & $v(\mathrm{CC})(51)+\beta(\mathrm{CH})(29)+v(\mathrm{CCl})(10)$ & 1098/1085/1067 & 1077 & 66.74 \\
\hline $16\left(A^{\prime}\right)$ & $\beta(C C)(51)+v(C C)(30)+v(C C I)(10)$ & 1035 & 1019 & 29.60 \\
\hline $17\left(A^{\prime \prime}\right)$ & $\omega(\mathrm{CH})(91)$ & $1001 / 988$ & 1000 & 0.60 \\
\hline $18\left(A^{\prime \prime}\right)$ & $\gamma(\mathrm{CH})(90)$ & 949 & 964 & 0.04 \\
\hline $19\left(A^{\prime \prime}\right)$ & $\gamma(\mathrm{CH})(94)$ & 865 & 870 & 11.80 \\
\hline $20\left(A^{\prime}\right)$ & $v(\mathrm{CC})(15)+v(\mathrm{C}-\mathrm{CHO})(15)+v(\mathrm{CBr})(10)$ & 836 & 822 & 94.53 \\
\hline $21\left(A^{\prime \prime}\right)$ & $\gamma(\mathrm{CH})(91)$ & 822 & 821 & 24.13 \\
\hline $22\left(A^{\prime}\right)$ & $\beta(C C)(52)+v(C C)(30)$ & 734 & 716 & 15.94 \\
\hline $23\left(A^{\prime \prime}\right)$ & $\gamma(C C)(90)$ & 692 & 692 & 0.84 \\
\hline $24\left(A^{\prime}\right)$ & $\beta(C C)(86)+v(C C I)(10)$ & $657 / 645$ & 649 & 1.93 \\
\hline $25\left(A^{\prime}\right)$ & $\beta(C C)(40)+v(C B r)(40)+v(C C l)(10)$ & 568 & 553 & 10.53 \\
\hline $26\left(A^{\prime \prime}\right)$ & $\gamma(\mathrm{CC})(85)+\gamma(\mathrm{C}-\mathrm{CHO})(10)$ & 542 & 546 & 2.00 \\
\hline $27\left(A^{\prime \prime}\right)$ & $\gamma(\mathrm{CC})(68)+\gamma(\mathrm{C}-\mathrm{CHO})(18)$ & 436 & 440 & 6.90 \\
\hline
\end{tabular}

$v, \beta, \gamma, \rho, \omega$ and $\tau$ denote stretching, in plane bending, out of plane bending, rocking, wagging and torsion, respectively according to the scaling factors of the present study and literature whereas it was computed as $33 \mathrm{~cm}^{-1}$ for this level in literature [42].

Turning to the solvent scales for the carbonyl stretching frequencies, there is a linear correlation between theoretical frequencies and KBM parameters for both 18 solvents $\left(1718.58-48.60 f(\varepsilon)\right.$ and $\left.R^{2}: 0.99698\right)$ and for 8 solvents employed (1718.47-48.54 $f(\varepsilon)$ and $\left.R^{2}: 0.99637\right)$. There is a good relationship and the negative slope in these equations show that all theoretical frequencies are red shifted while the dielectric constants of solvents increase. KBM considers only the dielectric constant of the solvent and the good correlation shows that PCM model is suitable to probe dielectric constant-induced solvent effects. However, when the experimental data of 2-bromo-4-chlorobenzaldehyde are evaluated by $\mathrm{KBM}$, there is no linear correlation between experimental frequencies and the KBM parameters. It means that specific and nonspecific solvent effects collectively contribute to solute-solvent interactions and it is inadequate to use single solvent parameter to describe them. Therefore, the single-parameter KBM equation is insufficient to provide an overall description of solvent effects of 2-bromo4-chlorobenzaldehyde. Similar results were reported for both experimental $[25,27,29,31,33,34]$ and theoretical data [34-37] of KBM scales of various compounds. Meanwhile, the AN scale which handles only acidity of the solvent shows poor correlation (1706.92-0.34 AN and $R^{2}$ : 0.57360 ) for theoretical frequencies of 18 solvent systems as shown previously $[25-27,31-33,37]$ whereas there is a linear correlation between theoretical frequencies and AN' parameters for the system of 8 solvents (1709.42-0.36 $A N R^{2}$ : 0.98894). However, analogously there is no linear 
Fig. 2 Experimental (a) and theoretical (b) IR spectra of 2-bromo-4-chlorobenzaldehyde
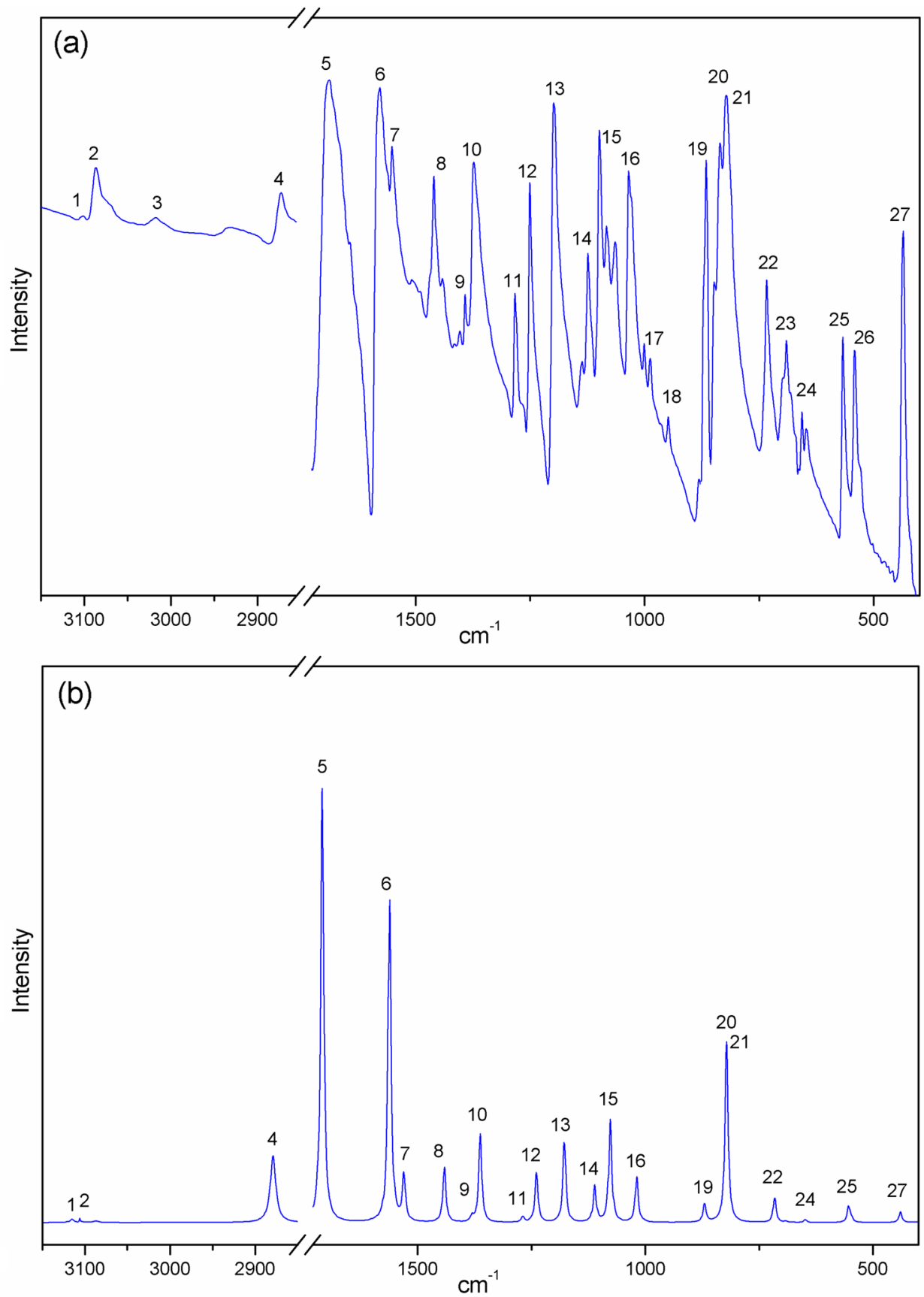

correlation between the experimental frequencies and parameters of $\mathrm{AN}$ equation.

Moving to the theoretical carbonyl stretching frequencies both for 18 solvents $(1710.08-16.28 \mathrm{Aj}-7.51 \mathrm{Bj}$ and $\left.R^{2}: 0.73485\right)$ and for 8 solvents employed (1709.22-20.92 $A j+1.02 B j$ and $R^{2}: 0.98511$ ) of Swain equation which considers only specific solute-solvent interactions such as acidity and basicity, the experimental data $(1705.92+2.13$ $A j-9.74 B j$ and $R^{2}: 90560$ ) help to achieve a realistic assessment. Although the correlation of Swain equation with the experimental data is poor, it is better than those obtained with KBM and AN [34]. Positive and negative signs of the coefficients represent the blue and red frequency shifts due to the solvent acidity and basicity.

Turning to the LSER solvent scale which considers both specific and non-specific interaction parameters, there are linear and good correlations between theoretical and experimental carbonyl stretching frequencies for the 8 solvents employed whereas there is poor correlation for theoretical data of the 18 solvents. Theoretical and experimental LSER equations are given as follows; 
Fig. 3 Experimental IR spectra of carbonyl stretching vibration of 2-bromo-4-chlorobenzaldehyde in non-polar (a) and polar (b) solvents
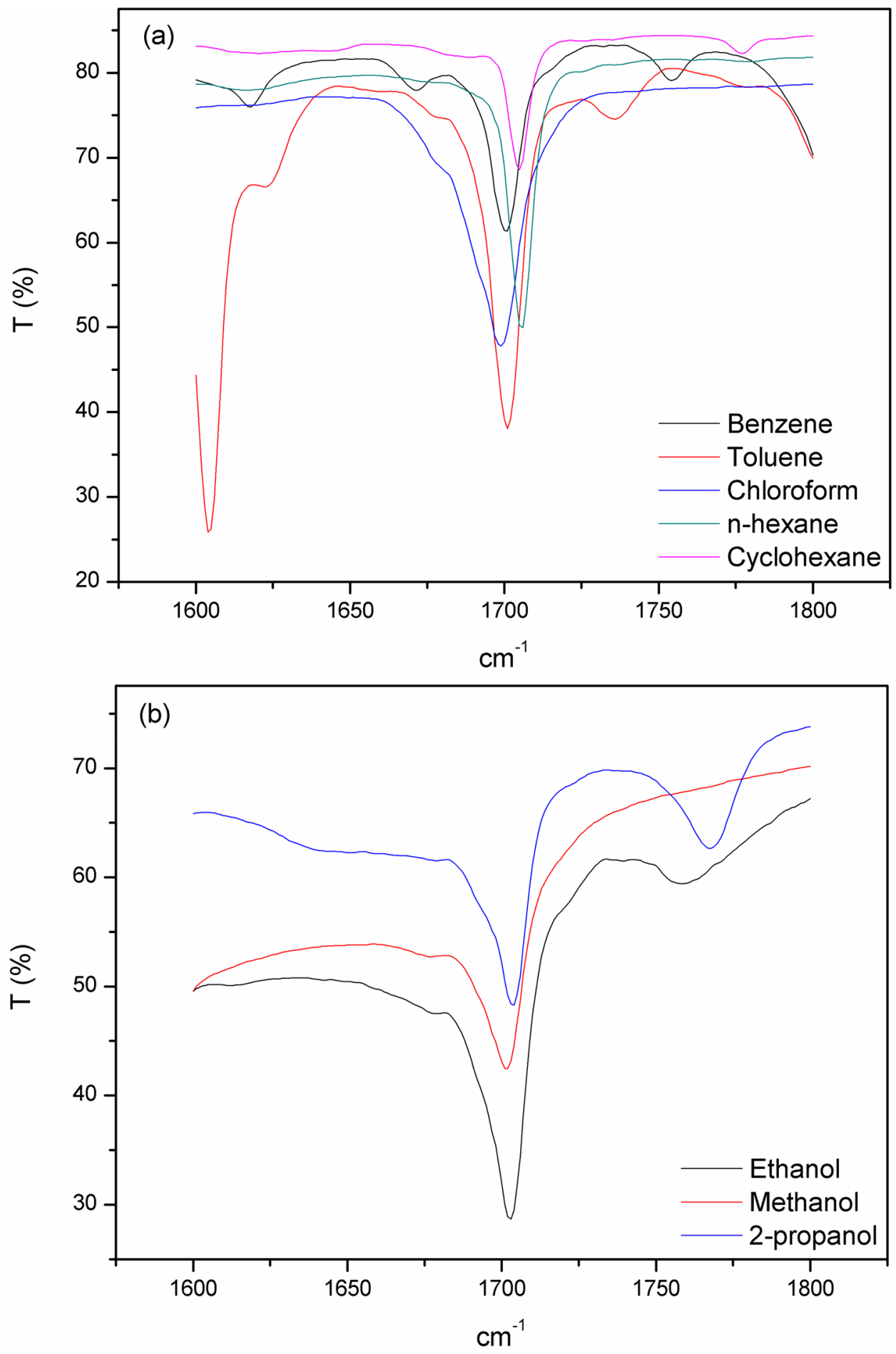

$1709.07-13.34 \pi^{*}+5.13 \delta-4.39 \alpha-3.73 \beta\left(R^{2}: 0.8143\right.$ for 18 solvents theoretically $)$

$1708.49-23.46 \pi^{*}+12.18 \delta+3.76 \alpha-4.57 \beta\left(R^{2}: 0.98810\right.$ for 8 solvents theoretically)

$1705.15-16.67 \pi^{*}+4.74 \delta+3.76 \alpha+4.78 \beta\left(\mathrm{R}^{2}: 0.97203\right.$ for 8 solvent experimentally $)$ 
Negative $\pi^{*}$ coefficients as non-specific solvent effect mean that frequencies shift the red region. Hence, the parameters of non-specific interaction such as dielectric constant on the carbonyl stretching frequencies displays a larger effect than parameters of specific interaction such as acidity or basicity. Positive and negative signs represent blue and red shifts of the carbonyl frequencies. When comparing the acidity and basicity regression coefficients, it is concluded that carbonyl frequencies are more susceptible to basicity of the solvents than the acidity.

Both the Swain and LSER models exhibit linear correlations together with experimental data whereas theoretical values show linear correlations with KBM scale. LSER model have also shown similar and good linear results in previous studies $[25-27,29,31-37]$. These indicate that specific and non-specific solute-solvent interactions collectively contribute to the solvent interaction.

\section{Conclusions}

An experimental and theoretical study of the IR spectral data, solvent effect on carbonyl stretching and conformer of 2-bromo-4-chlorobenzaldehyde can be summarized as the follows:

1. Conformational preference is independent on the solvent and theory employed.

2. Carbonyl frequencies exhibit linear correlations with dipole moment of the compound $\left(R^{2}: 0.99746\right)$.

3. The computation of $6-311+G(3 d f, p)$ basis set with B3LYP functional for the gas phase is reliable and complement the understanding of IR spectra. The R-square values for IR data is found to be 0.99964 . RMSD value for theoretical and experimental frequencies is found as $12.47 \mathrm{~cm}^{-1}$.

4. B3LYP/6-31G $(d, p)$ calculations in solutions show excellent agreement with the experimental data for the carbonyl stretching frequencies. Scaling factor for this level is computed as 0.9595 . RMSD value for the experimental and theoretical carbonyl stretching frequencies is found as $5.73 \mathrm{~cm}^{-1}$.

5. With the help of experimental data, an excellent correlation is observed between carbonyl frequencies and LSER parameters while KBM scale show successful correlation together with the theoretical values. Thus, LSER scale gives physically meaningful explanation of solute-solvent interaction and it proves a quantitatively accurate and allows the theoretical prediction for such classes of the compound.

Acknowledgements We acknowledge Fencluster system of Ege University for the calculations. This work was supported by Ege
University Scientific Research Projects Coordination Unit (Project Number: FGA_2019_20390).

\section{Compliance with ethical standards}

Conflict of interest The authors declare that they have no competing interests.

\section{References}

1. Lobato Silva LF, Paschoal W Jr, Pinheiro GS, da Silva Filho JG, Freire PTC, de Sousa FF, Moreira SGC (2019) Understanding the effect of solvent polarity on the polymorphism of octadecanoic acid through spectroscopic techniques and DFT calculations. CrystEngComm 21:297-309

2. Seitsonen AP, Idrissi A, Protti S, Mezzetti A (2019) Solvent effects on the vibrational spectrum of 3-hydroxyflavone. J Mol Liq 275:723-728

3. Bilkan MT, Şahin O, Yurdakul Ş (2017) Experimental and DFT studies of solvent effects on molecular structure and physical properties of dipyridylamine pyridine based ligand. J Mol Struct 1133:580-590

4. Davies JA, Besley NA, Nicholas A, Yang SF, Ellis AM (2019) Infrared spectroscopy of a small ion solvated by helium: $\mathrm{OH}$ stretching region of $\mathrm{He}_{\mathrm{N}}-\mathrm{HOCO}^{+}$. J Chem Phys 151:194307

5. Smith BC (2017) The carbonyl group, part I: introduction. Spectroscopy 32:31-36

6. Parlak C, Kumar CSC, Fun HK, Kesan G, Rhyman L, Ramasami P, Chandraju S, Quah CK (2014) 4-chloro-3-fluorobenzaldehyde: experimental (XRD, FT-IR and Raman) and DFT studies. J Fluor Chem 163:7-15

7. Tursun $M$, Kumar CSC, Bilge $M$, Rhyman L, Fun HK, Parlak $C$, Ramasami P, Chandraju S, Quah CK (2015) Crystal structure, vibrational spectra and DFT simulations of 2-fluoro-4-bromobenzaldehyde. Spectrochim Acta A 146:342-349

8. Aralakkanavar MK, Katti NR, Jeergal PR, Kalkoti GB, Rao R, Shashidhar MA (1992) $\pi^{*} \leftarrow \pi$ systems in the electronic absorption spectra of some trisubstituted benzenes. Spectrochim Acta A 48:983-991

9. Samdal S, Strand TG, Tafipolsky MA, Vilkov LV, Popik MV, Volden HV (1997) The molecular structure of benzene derivatives part 1. 4-fluorobenzaldehyde by joint analysis of gas electron diffraction, microwave spectroscopy and ab initio molecular orbital calculations. J Mol Struct 435:89-99

10. Mollendal H, Gundersen S, Tafipolsky MA, Volden HV (1998) The molecular structure of benzene derivatives, part 2: 4-chlorobenzaldehyde by joint analysis of gas electron diffraction, microwave spectroscopy and ab initio molecular orbital calculations. J Mol Struct 444:47-56

11. Anjaneyulu A, Rao GR (1999) Vibrational analysis of substituted benzaldehydes: part I. Vibrational spectra, normal co-ordinate analysis and transferability of force constants of monohalogenated benzaldehydes. Spectrochim Acta A 55:749-760

12. Marques MPM, Amorim da Costa AM, Ribeiro-Claro PJA (2001) Evidence of $\mathrm{C}-\mathrm{H} \cdots \mathrm{O}$ hydrogen bonds in liquid 4-ethoxybenzaldehyde by NMR and vibrational spectroscopies. J Phys Chem A 105:5292-5297

13. Akai N, Kudoh S, Takayanagi M, Nakata M (2002) Photoinduced rotational isomerization mechanism of 2-chlorobenzaldehyde in low-temperature rare-gas matrices by vibrational and electronic spectroscopies. J Photochem Photobiol, A 150:93-100 
14. Bednarek P, Bally T, Gebicki J (2002) Characterization of rotameric mixtures in o- and m-substituted benzaldehydes by matrix isolation IR spectroscopy. J Org Chem 67:1319-1322

15. Rao PVR, Rao GR (2002) Vibrational analysis of substituted phenols: part II. Transferability of valence force constants. Spectrochim Acta A 58:3205-3221

16. Speakman LD, Papas BN, Woodcook HL, Schaefer HF (2004) The microwave and infrared spectroscopy of benzaldehyde: conflict between theory and experimental deductions. J Chem Phys 120:4247-4250

17. Qayyum M, Reddy BV, Rao GR (2004) Vibrational analysis of mononitro substituted benzamides, benzaldehydes and toluenes: part I. Vibrational spectra, normal coordinate analysis and transferability of force constants of nitrobenzamides, nitrobenzaldehydes and nitrotoluenes. Spectrochim Acta A 60:279-290

18. Itoh T, Akai N, Ohno K (2006) Infrared spectra of p-, m-and o-fluorobenzaldehyde in low temperature argon matrices. J Mol Struct 786:39-45

19. Hiremath CS, Yenagi J, Tonannavar J (2007) FT-Raman and infrared spectra and vibrational assignments for 3-chloro-4-methoxybenzaldehyde, as supported by ab initio, hybrid density functional theory and normal coordinate calculations. Spectrochim Acta A 68:710-717

20. Kirkwood JG, Edwards RT (1937) The infrared absorption spectrum of hydrogen chloride in solution. J Chem Phys 5:14-22

21. Gutmann V, Resch G (1978) The donor-acceptor interactions. Plenum Press, New York

22. Swain CG, Swain MS, Powell AL, Alunni S (1983) Solvent effects on chemical reactivity. Evaluation of anion-and cation-solvation components. J Am Chem Soc 105:502-513

23. Kamlet MJ, Abboud JLM, Abraham MH, Taft RW (1983) Linear solvation energy relationships. 23. A comprehensive collection of the solvatochromic parameters,pi. ,alpha., and.beta., and some methods for simplifying the generalized solvatochromic equation. J Org Chem 48:2877-2887

24. Cappelli C, Silva CO, Tomasi J (2001) Solvent effects on vibrational modes: ab initio calculations, scaling and solvent functions with applications to the carbonyl stretch of dialkyl ketones. J Mol Struct 544:191-203

25. Liu Q, Sang W, Xu X (2002) Solvent effects on infrared spectra of 5-methyl-7-methoxy-iso-flavone in single solvent systems. J Mol Struct 608:253-257

26. Liu Q, Xu X, Sang W (2003) Solvent effects on infrared spectra of 2-acetylthiophene in organic solvents. Spectrochim Acta A 59:471-475

27. Tekin N, Cebe M (2004) Solvents effect on infrared spectra of trimethyl phosphate in organic solvents. Vib Spectrosc 36:129-133

28. Liu Q, Zheng JP, Fang DJ (2004) Solvent effects on infrared spectra of methyl methacrylate. Spectrosc Lett 37:225-233
29. Tekin N, Namli H, Turhan O (2005) Solvents effect on infrared spectra of 1, 3-indanedione in organic solvents. Vib Spectrosc 39:214-219

30. Dharmalingam K, Ramachandran K, Sivagurunathan P (2006) FTIR study of molecular interaction in butyl methacrylateorganic solvents mixtures. Z Phys Chem 220:739-748

31. Ji X, Li Y, Zheng J, Liu Q (2011) Solvent effects of ethyl methacrylate characterized by FTIR. Mater Chem Phys 130:1151-1155

32. Jovic B, Nikolic A, Petrovic S (2013) FTIR spectroscopic study of hydrogen bonding and solvent induced frequency shifts of N-tert-butylacetamide. J Mol Struct 1044:140-143

33. Tekin N, Pir H, Sagdin S (2012) Study of the solvent effects on the molecular structure and $\mathrm{CO}$ stretching vibrations of flurbiprofen. Spectrochim Acta A 98:122-131

34. Chen Y, Zhang H, Liu Q (2014) FT-IR spectroscopy combined with DFT calculation to explore solvent effects of vinyl acetate. Spectrochim Acta A 126:122-128

35. Shabani M, Ghiasi R, Yousefi M, Ketabi S (2017) A computational understanding of solvent effect on the structure, electronic, thermochemical, and spectroscopic properties of $\mathrm{Ni}\left(\mathrm{n}^{2}-\mathrm{C} 6 \mathrm{H} 4\right)$ $(\mathrm{H} 2 \mathrm{PCH} 2 \mathrm{CH} 2 \mathrm{PH} 2)$ complex. J Chin Chem Soc 64:925-933

36. Ghiasi R (2018) Exploration of solvent effects on the spectroscopic properties (Ir and 13C NMR) in the OsCl3( $\equiv \mathrm{CCH} 2 \mathrm{CMe} 3$ ) (PH3)2 carbyne complex. J Struct Chem 59:1052-1057

37. Parlak C (2017) Solvent effects on the NH stretching of 1-(4-pyridyl) piperazine. J Struct Chem 58:167-172

38. Fernández D, Parlak C, Bilge M, Kaya MF, Tursun M, Keşan G, Rhyman L, Ramasami P, Şenyel M (2017) Molecular, vibrational and electronic structure of 4-bromo-2-halogenobenzaldehydes: halogen and solvent effects. Phys Sci Rev 2:20170058

39. Tursun M, Parlak C (2015) Conformation stability, halogen and solvent effects on $\mathrm{CO}$ stretching of 4-chloro-3-halogenobenzaIdehydes. Spectrochim Acta A 141:58-63

40. Frisch MJ, Trucks GW, Schlegel HB et al (2009) Gaussian 09, revision A.1. Gaussian Inc., Wallingford

41. Jamróz MH (2013) Vibrational energy distribution analysis (VEDA): scopes and limitations. Spectrochim Acta A 114:220-230

42. Merrick JP, Moran D, Radom L (2007) An evaluation of harmonic vibrational frequency scale factors. J Phys Chem A 111:11683-11700

Publisher's Note Springer Nature remains neutral with regard to jurisdictional claims in published maps and institutional affiliations. 